\title{
Ethylene glycol assisted spray pyrolysis for the synthesis of hollow $\mathrm{BaFe}_{12} \mathrm{O}_{19}$ spheres
}

\author{
Xia Xu ${ }^{\mathrm{a}, \mathrm{b}}$, Jihoon Park ${ }^{\mathrm{a}, \mathrm{c}}$, Yang-Ki Hong ${ }^{\mathrm{a}, \mathrm{c}}$, Alan M. Lane $\mathrm{e}^{\mathrm{a}, \mathrm{b}^{*}}$
}

${ }^{a}$ Center for Materials for Information Technology, The University of Alabama, Tuscaloosa, AL 35487 USA.

${ }^{b}$ Department of Chemical and Biological Engineering, The University of Alabama, Tuscaloosa, AL 35487 USA.

${ }^{\mathrm{c}}$ Department of Electrical and Computer Engineering, The University of Alabama, Tuscaloosa, AL 35487 USA.

\begin{abstract}
Hollow spherical $\mathrm{BaFe}_{12} \mathrm{O}_{19}$ particles were synthesized by spray pyrolysis from a solution containing ethylene glycol (EG) and precursors at $1000{ }^{\circ} \mathrm{C}$. The effects of EG concentration on particle morphology, crystallinity and magnetic properties were investigated. The hollow spherical particles were found to consist of primary particles, and higher EG concentration led to a bigger primary particle size. EG concentration did not show much effect on the hollow particle size. Better crystallinity and higher magnetic coercivity were obtained with higher EG concentration, which is attributed to further crystallization with the heat produced from EG combustion. Saturation magnetization (emu/g) decreased with increasing EG concentration due to residual carbon from EG incomplete combustion, contributing as a non-magnetic phase to the particles.
\end{abstract}

KEYWORDS: Magnetic materials; Nanocrystalline materials; Particles, nanosize; X-ray techniques.

\footnotetext{
* Corresponding author contacted by telephone: +1-205-348-6367, fax: +1-205-348-7558 and email: alane@eng.ua.edu. Postal address: 245 7th Avenue, 360 H.M. Comer, Tuscaloosa, AL 35487-0203, the United States of America.
} 


\section{Introduction}

Hexagonal barium ferrite $\left(\mathrm{BaFe}_{12} \mathrm{O}_{19}\right)$ has been of a great interest because of its good magnetic properties, low cost, and high chemical and physical stability. Various preparation methods have been proposed to synthesize $\mathrm{BaFe}_{12} \mathrm{O}_{19}$ particles, such as ceramic [1-3], co-precipitation [4-6] and spray pyrolysis [7, 8] methods. Compared with other synthesis techniques, spray pyrolysis has several advantages including simple operation, high purity, excellent control of chemical uniformity and stoichiometry in mixed oxide systems, and continuous operation [9]. The product properties are affected by factors such as carrier gas type and flow rate, pyrolysis temperature, concentration of the spray solution and types of organic additives [10].

An organic additive is well known to produce a large amount of gas inside the droplet while flowing through the high temperature reactor and makes the products hollow [10]. Citric acid (CA), ethylenediaminetetraacetic acid (EDTA), ethylene glycol (EG), polyethylene glycol (PEG) and ethanol alone or in combination have been used in organic-assisted spray pyrolysis to synthesize metal oxides, and different organics lead to different morphologies of the products $[8$, 11-16]. EG-assisted spray pyrolysis has never been applied to $\mathrm{BaFe}_{12} \mathrm{O}_{19}$ synthesis, and previous research of organic-assisted spray pyrolysis mainly focuses on different reaction temperatures [8, 11-16]; the effects of organic concentration are rarely investigated. In this study, we applied EG-assisted spray pyrolysis to $\mathrm{BaFe}_{12} \mathrm{O}_{19}$ particle synthesis and studied the effects of EG concentration in the precursor solution on product morphology, crystallization and magnetic properties. As an example application, due to the high chemical and physical stability, as well as 
large surface area, the hollow $\mathrm{BaFe}_{12} \mathrm{O}_{19}$ spheres can be potentially used as catalysts supports. The magnetic properties of hollow $\mathrm{BaFe}_{12} \mathrm{O}_{19}$ spheres provide an effective way to collect and recycle the catalysts.

\section{Method and Characterization}

\subsection{Synthesis of hollow $\mathrm{BaFe}_{12} \mathrm{O}_{19}$ spheres}

The synthesis of spherical $\mathrm{BaFe}_{12} \mathrm{O}_{19}$ particles is based on a previous report [17] with little modification . Generally, $\mathrm{Fe}\left(\mathrm{NO}_{3}\right)_{3} \cdot 9 \mathrm{H}_{2} \mathrm{O}(4.84$ g, Sigma, assay: $99.99 \%)$ and $\mathrm{Ba}\left(\mathrm{NO}_{3}\right)_{2}$ ( $0.27 \mathrm{~g}$, Sigma assay: $\geq 99 \%)$ were dissolved in $100 \mathrm{~mL}$ solvent consisting of $\mathrm{DI}_{2} \mathrm{O}$ (RICCA, ASTM Type II) and ethylene glycol (EG, BHD, assay: > 99.99\%). The volume percentage of EG was controlled to 10,20 and $30 \%$. The solution was then transferred to an ultrasonic nebulizer (Intertek, $1.7 \mathrm{MHz}$ ) to generate fine and uniform liquid droplets. In room air pulled by building vacuum at the end of the system, the droplets flowed through a tube furnace (length: $1.0 \mathrm{~m}$; inner diameter: $0.08 \mathrm{~m}$ ) at $1000{ }^{\circ} \mathrm{C}$ to thermally decompose the precursors and produce $\mathrm{BaFe}_{12} \mathrm{O}_{19}$ particles. The flow rate was controlled to $5 \mathrm{~L} / \mathrm{min}$. The product was then cooled down by a heat exchanger, and finally collected by a fiber filter.

\subsection{Powder Characterization}

The powder X-ray diffraction (XRD) pattern was recorded by a Bruker D8 diffractometer using $\mathrm{Cu}-\mathrm{K} \alpha$ radiation $(\lambda=1.5406 \AA$ ). Transmission electron microscopy (TEM, TECHNAI FEI 20) was used to analyze the particle size and morphology. Scanning electron microscopy (SEM, 
JEOL 7000) and Energy Dispersive X-ray (EDX) spectroscopy were used to identify particle morphology and residual carbon in the products. Magnetic properties were checked at room temperature with a vibrating sample magnetometer (VSM, Microsense 3473-70) at an applied field of $2 \mathrm{~T}$.

\section{Results and discussion}

Figure 1 shows TEM images of $\mathrm{BaFe}_{12} \mathrm{O}_{19}$ particles synthesized from 10, 20 and 30 vol\% EG solutions. The low contrast of the particle surface indicates that most of the TEM electron beam passed through the particles, and confirms their hollow structure with a thin shell. The formation of a hollow structure can be explained by the temperature and concentration gradient along the radial direction of spray droplets in the pyrolysis process. Higher temperature on the droplet surface results in evaporation of the solvent and precursor concentration increasing within the droplet. Once the concentration is higher than the saturation concentration, the precursors precipitate on the droplet surface, thereby, forming a hollow structure [16]. Low magnification TEM images of Figs. 1a, $\mathrm{d}$ and $\mathrm{f}$ show that the particles are submicron size, and the size distribution is wide. EG concentration does not have an obvious effect on particle size, however, it does have obvious effects on particle morphology. All of the particles are hollow spheres at 10 vol\% EG. When the concentration increases to 20 and 30 vol\%, crystal pieces are mixed with hollow spheres in the products and higher EG concentration leads to a bigger amount of crystal pieces. During the pyrolysis process, high EG concentrations will oxidize and lead to too much pressure inside the droplet that we assume breaks the structure. Particles from 
different EG concentrations in Figs. 1b, e and h are spherical and hollow, and consist of many primary particles. The primary particles bridge with each other and form condensed hollow structured particles, as shown in Figs. 1c, f and i. Furthermore, the primary particle size from 10 vol\% EG (Fig. 1c, 20 nm) is smaller than those from 20 and 30 vol\% EG (Figs. 1f and i, 40 $\mathrm{nm})$, and the reason is still unknown.

Figure 2 shows the $\mathrm{X}$-ray diffraction patterns of the hollow $\mathrm{BaFe}_{12} \mathrm{O}_{19}$ spheres synthesized from different EG concentrations. All the samples present a clear pattern corresponding to standard hexagonal phase $\mathrm{BaFe}_{12} \mathrm{O}_{19}$ listed in JCPDS card (NO. 39-1433). The mean primary crystallite size of these three samples was calculated from Figs. 2a, b and c using the Scherrer Equation to be $25.3 \mathrm{~nm}, 42.7 \mathrm{~nm}$ and $46.1 \mathrm{~nm}$, matching well with the TEM images of Figs. 1c, f and i. It is known that post annealing is necessary to further crystallize the products from spray pyrolysis, since the residence time inside the furnace is too short to achieve a complete crystallization $[8,11,13]$. Interestingly, the particles produced in this research are well crystallized, especially at higher EG concentration. This could be attributed to the heat produced from the oxidation of EG inside the furnace. At higher EG concentration, more heat is produced and the products are better crystallized. Therefore, the peak intensity becomes higher with increased EG concentration, as shown in XRD patterns in Fig. 2.

The magnetic hysteresis loops of hollow $\mathrm{BaFe}_{12} \mathrm{O}_{19}$ spheres synthesized from different EG concentrations are shown in Fig. 3. The typical hard magnetic properties match well with pure hexagonal phase $\mathrm{BaFe}_{12} \mathrm{O}_{19}$ in XRD patterns of Fig. 2. The saturation magnetization is 62 $\mathrm{emu} / \mathrm{g}$ and coercivity is $3155 \mathrm{Oe}$ when the EG is $10 \mathrm{vol} \%$. With concentration increasing, the 
saturation magnetization decreases while the magnetic coercivity increases, arriving at $49 \mathrm{emu} / \mathrm{g}$ and 4284 Oe when the EG is $30 \mathrm{vol} \%$. A short residence time usually leads to incomplete combustion of organics, leaving carbon in the products. Higher EG concentration also leaves a larger amount of carbon in the products, contributing as a non-magnetic phase to the particles, and leading to decreased magnetization. Figs. $4 \mathrm{a}, \mathrm{b}$ and $\mathrm{c}$ show the SEM images of hollow $\mathrm{BaFe}_{12} \mathrm{O}_{19}$ spheres synthesized from different EG concentrations. The residual carbon and its quantity are confirmed by EDX spectroscopy, as shown in Figs. 4d, e and f, and the scanning time of all samples is controlled to one minute. The red dots confirm the existence of carbon, and the dot density represents the quantity. With increasing EG concentration, the density of the red dots increases, indicating a larger amount of residual carbon. The increased coercivity in Fig. 3 is due to better crystallization, which is in good agreement with the increased XRD peak intensity Fig. 2.

\section{Conclusions}

Hollow spherical $\mathrm{BaFe}_{12} \mathrm{O}_{19}$ particles were synthesized by EG-assisted spray pyrolysis with controlled EG concentrations. EG concentration does not affect the particle size but obviously affects the particle morphology. Higher EG concentration results in a better crystallization and more carbon left in the product, leading to an increase in coercivity and a decrease in magnetization. Compared with other organics, EG assisted spray pyrolysis provides a convenient way to control the morphology of the products, which is achieved by controlling the EG concentration in precursor solutions. 


\section{Acknowledgement}

This work was supported in part by the U.S. Department of Energy ARPA-E REACT Program under Award Number DE-AR0000189. This work utilized SEM, TEM and XRD owned and maintained by the Central Analytical Facility, which is supported by The University of Alabama. 


\section{Reference}

[1] Lisjak D. J. Eur. Ceram. Soc. 2012;32:3351-60.

[2] Zhang HJ, Jia XL, Ya X, Zhang LY. Key. Eng. Mat. 2005;280-283:457-60.

[3] Matutes-Aquino JA, Botello-Zubiate ME, Corral-Flores V, de Frutos J, Cebollada F, Menendez E, et al. Integr. Ferroelectr. 2008;101:22-8.

[4] Janasi SR, Rodrigues D, Landgraf FJG, Emura M. IEEE. T. Magn. 2000;36:3327-9.

[5] Janasi SR, Emura M, Landgraf FJG, Rodrigues D. J. Magn. Magn. Mater. 2002;238:168-72.

[6] Makled MH, Matsui T, Tsuda H, Mabuchi H, El-Mansy MK, Morii K. J. Cera. Soc. Jp. 2004;112:200-3.

[7] Cabanas MV, Gonzalezcalbet JM, Valletregi M. J. Mater. Res. 1994;9:712-6.

[8] Gonzalez-Carreno T, Morales MP, Serna CJ. Mater. Lett. 2000;43:97-101.

[9] Kang HS, Kang YC, Park HD, Shul YG. Mater. Lett. 2003;57:1288-94.

[10] Jung DS, Bin Park S, Kang YC. Korean. J. Chem. Eng. 2010;27:1621-45.

[11] Kang HS, Sohn JR, Kang YC, Jung KY, Park SB. J. Alloy. Compd. 2005;398:240-4.

[12] Lee KK, Kang YC, Jung KY, Kim JH. J. Alloy. Compd. 2005;395:280-5.

[13] Kim MH, Jung DS, Kang YC, Choi JH. Ceram. Int. 2009;35:1933-7.

[14] Yin XM, Li CC, Zhang M, Hao QY, Liu S, Li QH, et al. Nanotech. 2009;20.

[15] Ju SH, Kim DY, Jo EB, Kang YC. J. Mater. Sci. 2007;42:5369-74.

[16] Zhong K, Peabody G, Glicksman H, Ehrman S. J. Mater. Res. 2012;27:2540-50.

[17] Messing GL, Zhang SC, Jayanthi GV. J. Am. Ceram. Soc. 1993;76:2707-26. 


\section{Figures}
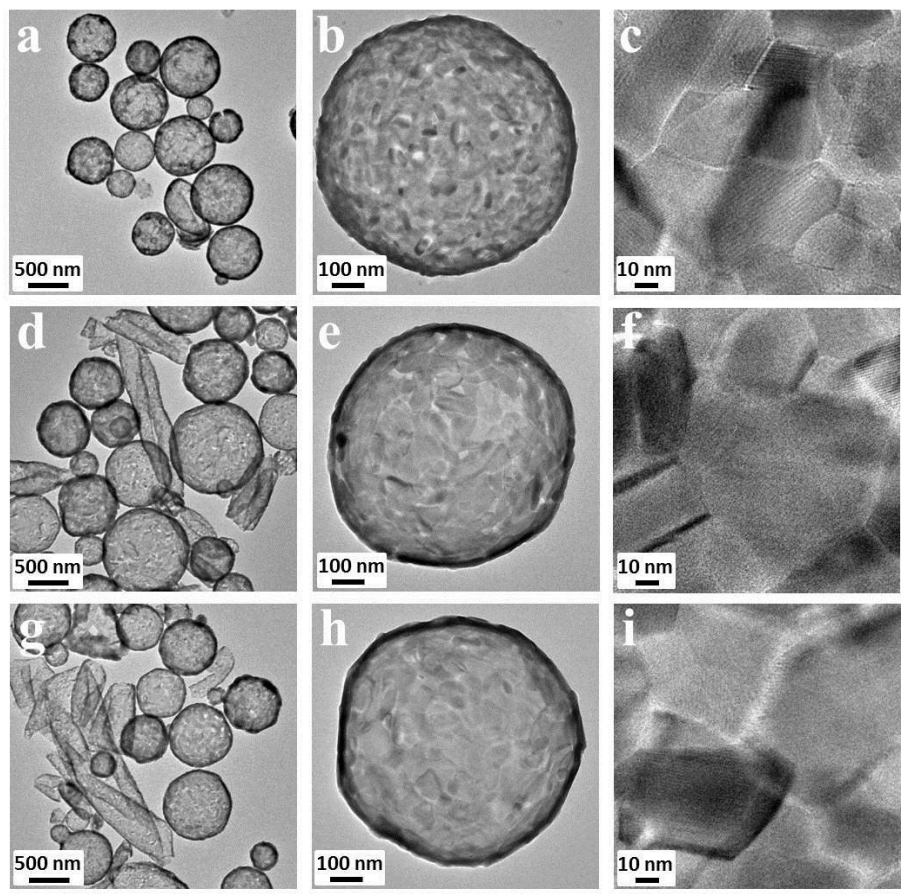

Fig. 1. TEM images of hollow $\mathrm{BaFe}_{12} \mathrm{O}_{19}$ spheres synthesized from $10 \mathrm{vol} \% \mathrm{EG}(\mathrm{a}, \mathrm{b}, \mathrm{c}), 20 \mathrm{vol} \%$ EG (d, e, f), and 30 vol\% EG (g, h, i). 


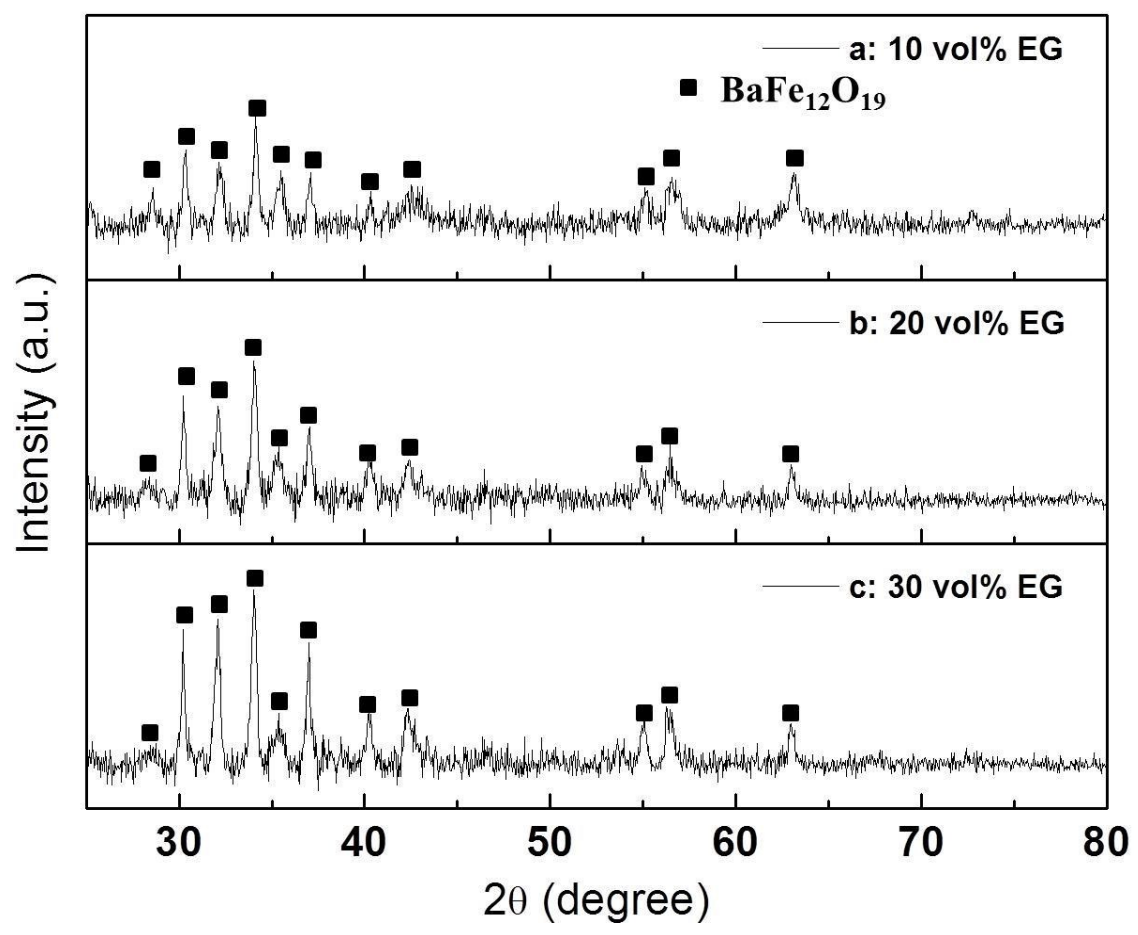

Fig. 2. X-ray diffraction patterns of hollow $\mathrm{BaFe}_{12} \mathrm{O}_{19}$ spheres synthesized from different concentrations of EG.

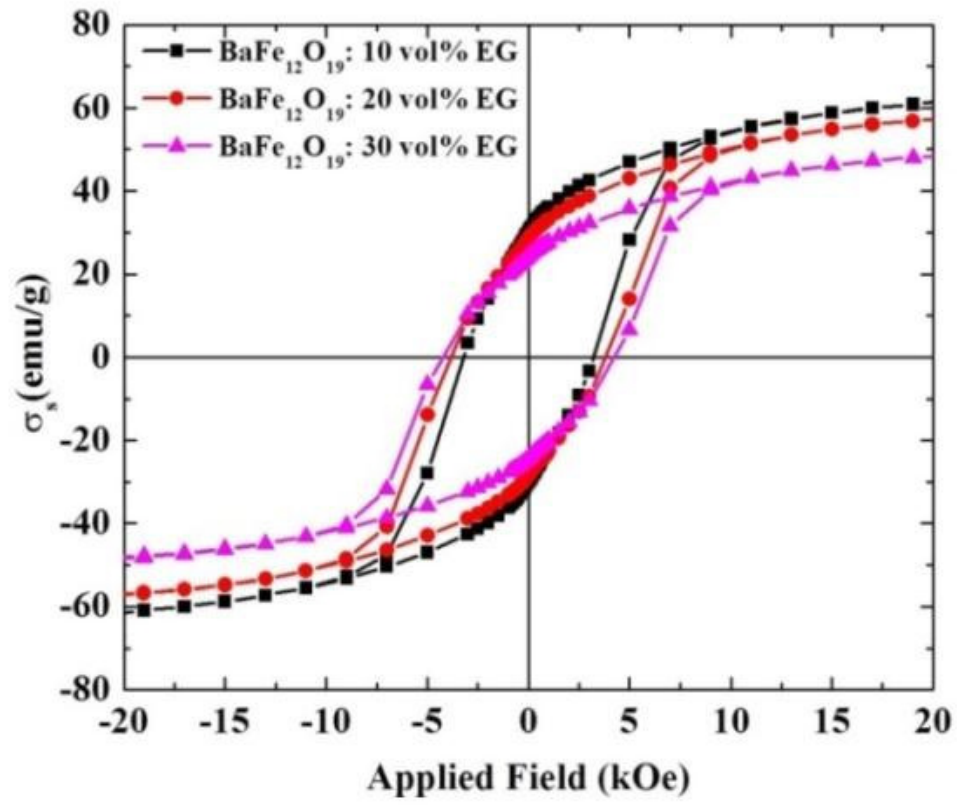


Fig. 3. Magnetic hysteresis loops of hollow $\mathrm{BaFe}_{12} \mathrm{O}_{19}$ spheres synthesized from different concentrations of EG.
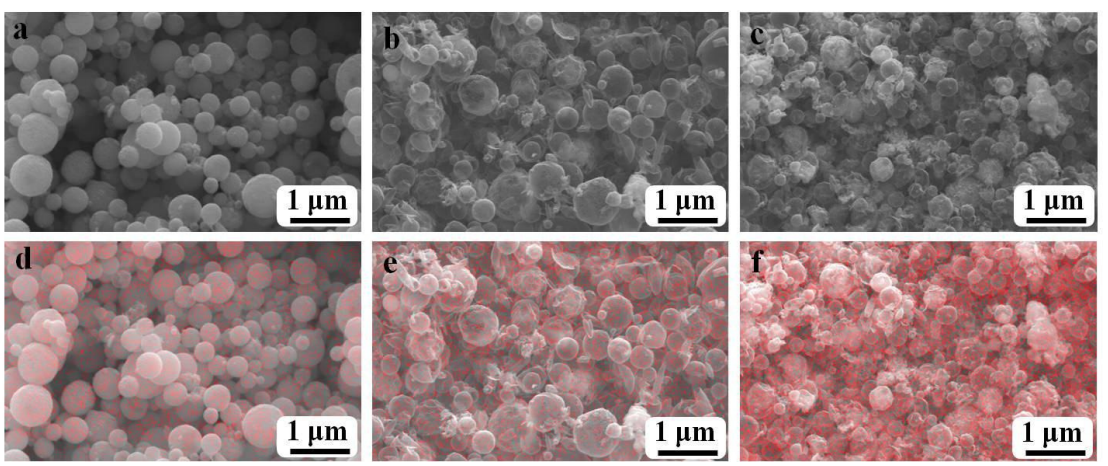

Fig. 4. SEM images (a, b, c) and their corresponding carbon EDX spectroscopy (d, e and f) of hollow $\mathrm{BaFe}_{12} \mathrm{O}_{19}$ spheres synthesized from $10(\mathrm{a}, \mathrm{d}), 20$ (b, e), and 30 (c, f) vol\% EG. 